\title{
A new load balancing scheduling model in data grid application
}

\begin{abstract}
Scheduling an application in data grid is significantly complex and very challenging because of its heterogeneous in nature of the grid system. Thus, Divisible Load Theory (DLT) is a powerful model for modeling data intensive grid problem where both communication and computation load is partitionable. Previously, Task Data Present (TDP) model was proposed based on DLT model. This paper presents an Adaptive TDP (ATDP) model to reduce the makespan. New equations for calculating the load allocation are derived. Experimental results showed that the proposed model can balance the load efficiently.
\end{abstract}

Keyword: Scheduling; Data grid; Adaptive TDP (ATDP) model; Load allocations 